\title{
Atlantis
}

Critical Studies in Gender, Culture \& Social Justice

Études critiques sur le genre, la culture, et la justice

\section{Gender, Victimization, and Commercial Sex: A Comparative Study}

\section{Tamara O'Doherty et Ian Waters}

Volume 40, numéro 1, fall 2019

URI : https://id.erudit.org/iderudit/1066418ar

DOI : https://doi.org/10.7202/1066418ar

Aller au sommaire du numéro

Éditeur(s)

Mount Saint Vincent University

ISSN

1715-0698 (numérique)

Découvrir la revue

Citer cet article

O'Doherty, T. \& Waters, I. (2019). Gender, Victimization, and Commercial Sex: A Comparative Study. Atlantis, 40(1), 18-31. https://doi.org/10.7202/1066418ar
Résumé de l'article

This article critically examines and compares adult male and female experiences selling sex in Canada's off-street sex industry. Findings indicate that gender disparities exist when it comes to the work of selling sex: male providers are better insulated from violence and exploitation because of their gender, while female sex workers are forced to navigate multiple layers of oppression to assure safer working conditions. Despite these differences, this data suggests that prioritizing overarching labour issues, instead of gendered experiences working in commercial sex, can function to increase all sex workers' safety and access to justice. 


\section{Research}

\section{Gender, Victimization, and Commercial Sex: A Comparative Study}

Tamara O'Doherty is a lecturer in the School of Criminology at Simon Fraser University.

Ian Waters is a master's student in the School of Public Policy at Simon Fraser University.

\begin{abstract}
This article critically examines and compares adult male and female experiences selling sex in Canada's off-street sex industry. Findings indicate that gender disparities exist when it comes to the work of selling sex: male providers are better insulated from violence and exploitation because of their gender, while female sex workers are forced to navigate multiple layers of oppression to assure safer working conditions. Despite these differences, this data suggests that prioritizing overarching labour issues, instead of gendered experiences working in commercial sex, can function to increase all sex workers' safety and access to justice.
\end{abstract}

Keywords: Sex work, gender, victimization, access to justice, labour rights

\section{Introduction}

Although the commercial sex industry has been subject to academic research for decades, few studies have employed overtly inclusive approaches. Until recently, studies typically focused on women's experiences selling sexual services-most often from the street-with some smaller projects including those who identified as male and sold sex, and even fewer that sought the experiences of transgender, non-binary, gender queer, or two-spirit sex workers. There are now several studies that include all gender identities and various forms of sex work (Benoit et al. 2014; Jeffrey and MacDonald 2006; Jenkins 2009; O'Doherty 2015; Sanders et al. 2018), and others that highlight the experiences of specific groups of workers, like racialized workers (Jones 2015; Lam 2018; Raguparan 2017). While there are ideological and political reasons for maintaining a narrow focus on women's experiences selling sex, operating from a more inclusive framework can help to better inform policy. To improve our understanding of how gender, criminality, and marginalization intersect, we need to know more about the degree to which the experience of selling sex is gendered, and which aspects of the work are comparable across genders.

The minimal attention in academic literature paid to the specific ways that gender impacts the experience of selling sex is particularly alarming when we consider how related laws and law enforcement reflect extremely gendered assumptions about the sex industry. For example, Canada is one of several countries to adopt a form of criminalization that is mostly in line with neo-prohibitionist targeting of the demand (clients) and management (third-parties) of sex work. However, those Canadians who provide sexual services remain directly criminalized under the communica- 
tion provision, and indirectly criminalized because their clients and those who assist them to do the work are targeted for criminalization. These latter provisions are particularly concerning given that social science evidence overwhelmingly demonstrates the harsh and negative impacts of criminalization (Maher, Pickering, and Gerard 2012; O'Doherty 2015; Pitcher 2015). Indeed, the Supreme Court of Canada determined that criminalization, in its direct and indirect forms, increased sex workers' vulnerability to victimization (Canada (AG) v Bedford, 2013 SCC 72). Unfortunately, and as critical legal scholars have been asserting for decades, law is political. The politicization of law is glaringly apparent in the legislation enacted after the Bedford decision: Canada now has one of the most expansive forms of criminalization in the world, demonstrating a flawed understanding of how criminalization contributes to victimization and marginalization.

The Canadian situation mirrors the international trend to enact asymmetrical criminalization on the assumption that sex work reflects deeply gendered, and misogynistic, social experiences. However, advocates have been basing these assertions on women's experiences alone, resulting in policy documents outlining laws that neglect to mention the existence of transgender or male sex workers (MSWs), in spite of the fact that they are estimated to comprise roughly 20-25 percent of any sex industry (Benoit et al 2014; Sanders et al. 2018). Further, the social science data that underlies asymmetrical criminalization tends to focus on women in the most marginalized circumstances (street-based workers), even though they comprise 5-20 percent of any sex industry (Pivot Legal Society 2006). These limitations in and of themselves are not terribly problematic as these samples reflect individuals who typically endure intersections of oppression such as racial prejudice, precarious housing and extreme poverty, addiction, mental health issues, and ongoing impacts of colonization (Kurtz et al. 2004; Lowman 2000; Pivot Legal Society 2006; Ross 2010; van der Meulen, Yee, and Durisin 2010). However, some academics continue to represent small samples of women selling sex in survival-type circumstances as if they were the only experiences for people who sell sex. Troublingly, this practice has been taken up by some advocates and politicians, and has resulted in unrepresentative, illinformed policies.

Social science research indicates that female sex workers (FSWs) experience higher rates of violence than MSWs experience (Benoit et al. 2014; O'Doherty 2015; Sanders et al. 2018; Walby 2012). However, other groups of sex workers also face harsh levels of victimization: transgender and non-binary sex workers often report victimization due in part to selling sex, but also due to their gender or gender presentation (Fletcher 2013; Lyons et al. 2017). Further, there are many women who sell sex and do not experience violence in their work (Benoit et al. 2014; Jenkins 2009; O'Doherty 2007; Sanders et al. 2018) and men who experience victimization related to selling sex (McIntyre 2005). Victimization rates ought to be considered in light of general inequality in society; women continue to face violence in their personal and sexual relationships at higher rates than do men-regardless of a commercial element in the transaction. Many other industries also feature high levels of exploitation and victimization for female labourers-but also of male or transgender labourers. While gender explains a degree of victimization, other socio-political factors such as class, race, and health may increase or decrease vulnerability, depending on the individual context.

When research related to commercial sex operates from a gender-inclusive perspective, new knowledge emerges that demonstrates less of a gender-based experience than previously represented in academic works. The conversation shifts away from a sole focus on the idea of females as vulnerable and in need of protection and allows exploration of the factors that can insulate workers from violence. Few studies have explored how the experience of selling sex, beyond victimization rates, is gendered. While there are studies representing men's experiences selling sex (Allman, 1999; Dorais 2005; Marińo, Minichiello, and Disogra 2004; Minichiello, Scott, and Callander 2013; 
MacPhail, Scott, and Minichiello 2015; Parsons, Koken, and Bimbi 2007; Pendleton and Stevenson 2016; Smith 2012; Smith, Grov, and Seal 2008; Walby 2012), they remain largely absent from general discourse and policy documents.

The literature surrounding MSWs often reflects different concerns than does the literature on FSW. Historically, academics have focused predominantly on the sexuality and sexual practices of the MSW and his capacity to spread communicable diseases (Bimbi 2007; Mariño, Minichiello, and Disogra 2004; Pendleton and Stevenson 2016). There is much to be gained from redirecting MSW discourse away from these foci and toward issues that more directly affect their work as sex workers, like regulatory frameworks and legal provisions (Minichiello, Scott, and Callander 2013; Pitcher and Wijers 2014). Past studies have rarely included male perspectives from a sex-work-as-work perspective, which means presumptions that men engage in sex work for pleasure, or sexual exploration, dominate the literature. This is troublesome since male providers experience similar stigma to that of female providers (Kumar et al. 2017), which can potentially lead to isolation (Pitcher and Wijers 2014), forced displacement (MacPhail, Scott, and Minichiello 2015; Ross 2010), police victimization (Gratl 2012), and increased vulnerability to violence (Lewis et al. 2005).

The sex industry encompasses individuals with diverse personal characteristics, motivations, and experiences; policies governing it ought to be evidence-based and reflective of this diversity. Since the emergence of the sex worker rights movement in the 1970s, sex workers and allies have been organizing and advocating to highlight sex work labour issues (Beer 2018). They continue to assert that criminalization frameworks perpetuate harm and prevent the implementation of safer working conditions (Krüsi et al. 2014; Landsberg et al. 2017; Levy and Jakobsson 2014; Sanders et al. 2018). While the evidence is clear, it reflects primarily the experiences of FSWs. This has facilitated the use of policies to affirm certain moral and ideological conceptions of fe- male vulnerability and a sustained drive to "protect" female sexual chastity. When men, transgender, twospirit, and other non-binary folks are included in policy discussions, protectionist discourse falls away and focus can be redirected towards ameliorating working conditions for all sex workers. In this article, we employ a gender-inclusive lens to unpack how socio-political positioning influences experiences of criminalization and victimization.

\section{Methods}

This article reports data collected as part of O'Doherty's (2015) collaboratively designed doctoral study investigating the experience of selling sex in Canada's off-street sex industry. Employing participant-driven action research methods, in line with current ethical practices (Bowen and O'Doherty 2014), the collaboration team (comprised of eight sex workers from across Canada) sampled 109 adult sex workers via an anonymous online survey and conducted 42 in-depth interviews in 2012 using purposive sampling. Participants were recruited using existing contact networks, publicly available lists of sex workers, and advertisements in online forums. The survey and interviews focused on victimization (defined as all forms of harm, in addition to inter-personal physical violence like theft or harassment) from clients, thirdparties, the state, and society more generally, as well as labour dimensions of sex industry work. In line with the Academy of Criminal Justice Sciences' ethics code, no limits were placed on the guarantee of confidentiality to participants. While the online questionnaire was anonymous, we use pseudonyms in all reporting to ensure interview participants remain un-identifiable.

This article also reports on Waters' (2018) related honours thesis findings which compared a subset of 11 male interview participants within O'Doherty's full sample with the other interview participants $(n=31)$, as well as to the other male $(n=12)$, female $(n=91)$, and transgender $(n=4)$ survey participants, to enable a more gender-inclusive understanding of sex industry work. Both projects received ethics approval through Simon Fraser University.

Issue 40.1/2019 


\section{Participants}

The participants worked in all segments of commercial sex, with many having experienced several forms of sex work. Their ages at the time of participation ranged from early 20 s to late 60 s. While the larger total sample included racialized sex workers, the sample of male participants was primarily white, with only one man identifying as non-white. Two transgender women and one gender queer woman participated in the project. However, these participants each indicated that their identities were most accurately framed as "women" for comparative reporting practices. Thus, this analysis is regrettably limited to a gender dichotomy. In terms of sexuality, the larger sample demonstrated similar diversity patterns as other recent works (Jenkins 2009; Sanders et al. 2018) with a large minority identifying as heterosexual $(42.6 \%)$, and the remainder of the participants identifying as bi-sexual, gay, lesbian, or queer. The male subset differed slightly: the majority identified as gay, with $30 \%$ of the total sample of survey and interview participants identifying as bisexual or as situationally open: hetero-flexible or "straight with a curve."

The following key findings challenge our current understanding of commercial sex generally and reveal distinctive characteristics of the male experience specifically. By comparing the data from the men to the overall sample, we provide a preliminary comparison of some male and female sex work experiences. We structure this report around the dominant themes present in the interview segment of the research: violence and victimization, occupational health and safety, and regulatory frameworks and their impacts on sex workers. Ultimately, this data demonstrates that the experience of selling sex reflects the degree to which one's socio-political identity produces relative advantage or disadvantage in different social contexts.

\section{Violence and Victimization}

\section{Rates of Victimization}

The overwhelming majority of men interviewed indicated that they felt safe from victimization and violence. Of the 11 interview participants, one experienced a violent encounter, and that encounter did not occur during the course of his sex work. Consequently, the mere association of male sex work and violence seemed ludicrous to some, as Sean expressed: "How can providing an intimate, pleasurable experience which in many cases can by luminous, transcendent, a sacrament - how can that be ... violence?"

Some of these participants described client interactions wherein they felt uncomfortable, yet when compared to the larger sample of sex worker experiences in the survey, these data confirm that male experiences of violence are markedly lower than those of FSWs. Whereas $33.7 \%$ of female survey respondents reported experiences of inter-personal violence, $25.0 \%$ of the men surveyed ( 3 out of 12) encountered violence during the course of their work in the sex industry (O'Doherty 2015, 159). These findings are consistent with related research: Minichiello et al. (1999) found that violence was an infrequent exception for MSWs, while Mariño, Minichiello and Disogra (2004) found that out of 254 MSW encounters, only $1.5 \%$ involved some form of violence.

While men experience low violence rates, like women, they face other forms of non-violent victimization (harassment, pressure to participate in sexual activities or provide unprotected sexual services, theft). However, FSWs continue to experience higher rates of both violent and non-violent victimization during the course of their work (O'Doherty 2015; Sanders et al. 2018). Walby (2012) hypothesizes that men face less victimization than females because MSW clients are typically other men. This hypothesis falls in line with the gendered nature of victimization at a societal level, wherein female victimization is seen as being an expression of power-something that is not generally present in interactions involving male providers (Bungay et al. 2012, 263). 
When participants in our study were asked about their clients and their propensity for violence, there was some disparity according to gender. The female participants were quick to point out the various riskmitigating activities they built into their work to prevent victimization, whereas the male participants were somewhat dismissive of any risk of violence from their clients, particularly their female clients. On the contrary, these participants-like sex workers in other studies (Jenkins 2009 and Redwood 2013)_asserted that their clients were respectful and that most clients would not dream of victimizing providers. In an earlier study, off-street FSWs likewise explained that client relations are generally very positive, with many participants expressing care for their clients and rejecting the view that clients are predators (O'Doherty 2007). The participants in this study explained that while clients frequently tried to negotiate prices or request specific sexual activities that the worker did not generally provide, workers most often responded by refusing to negotiate price, offering alternative services, or rejecting the client outright. In this regard, women spoke more assertively than did men. These male participants, having smaller pools of clients and often working part-time, expressed more openness to negotiation and "exploration." This confirms the importance of context in maintaining safety: in some situations, women providers felt relatively more power to refuse to negotiate with clients than did male providers.

In terms of third-parties, most of the male participants in our study worked independently, whereas women often spoke of working in cooperative environments, for agents, or in other managed environments. The independent workers reported the lowest rates of victimization and violence, again demonstrating the importance of situational privilege associated with both structure and context. Victimization can occur in any context, but sex workers' power to control the parameters of client interactions positively affects their safety, regardless of gender. Where the worker feels able to decline a client, especially when the worker feels that a manager or other person is present and able to support the worker, victimization is reduced (Bruckert and Law 2013; O’Doherty 2011).

These findings demonstrate that general experiences within the sex industry stand in contrast to claims made in government policy regarding the omnipresence of violence and victimization. The rates of victimization reported in this study support the notion that sex work is not inherently violent, nor is it necessarily an experience of sexual coercion, pimping, or trafficking. Therefore, victimization does not justify criminalization frameworks for the purposes of protection in this highly gendered and essentialist manner. Not only can standard criminal laws be used if violence occurs, criminalization impedes safer labour conditions by disallowing third-parties, who can play a crucial role in minimizing the risk of encountering occupational hazards (Anderson et al. 2015; Bruckert and Law 2013; Pitcher and Wijers 2014; Shaver, Lewis, and Maticka-Tyndale 2011).

\section{Mitigating Risk}

Many participants shared safety strategies they practiced to mitigate occupational hazards during the course of their work. Much like Corriveau and Greco (2014) found, participants reported employing approaches such as having tracking functions enabled on cell phones, telling others of a location, communicating with clients prior to meeting-up, establishing physical and psychological boundaries, and maintaining sobriety to minimize the risk of encountering victimization. Despite the comprehensiveness of these strategies, the male interview participants rarely expressed physical safety as a primary concern. Tony's response, "safety-I've never had a concern," reflects the responses typically provided by men in our study.

For FSWs, risk management strategies occupy a more central role. The women in the larger sample identified physical safety as being one of their top concerns, devoting considerable time to listing specific safetyenhancing strategies in their responses. While the women identified similar risk management strategies as did the MSWs, they also reported using more rigorous safety strategies to ensure their physical safety, 
such as requiring references, screening clients using bad date sheets, making safety calls, carrying pepper spray, and taking self-defence classes.

The differential emphasis placed on physical safety strategies relates to sex workers' abilities to respond to violence and non-violent victimization. Most participants explained that if they felt uncomfortable or unsafe in a situation, they simply reaffirmed their boundaries or otherwise asserted control over the encounter. If that did not ease their apprehension, they simply left. Some participants went on to explain that they would not hesitate to phone the police in the event of an incident. However, the reality of disclosing one's sex work status to police and the fear of facing legal repercussion, or even judgment from police, combined with a lack of faith in the Canadian legal system's ability to deal with their victimization, served as a barrier to reporting actual incidents of victimization. Privilege is one factor here, as Sean explains the different responses from police to victimization faced by racialized sex workers in particular: "I'm the sort of person (a white, cisgender male) who could create a real fucking stink if they didn't do something about it. ... Because of my privilege, I could probably report. But not everyone has access to justice."

Gender was not a primary differentiating factor in reporting practices, either. MSWs, who typically did not experience violence, remained concerned about police reactions to their sex work. Some men felt that they would be treated poorly because they were gay or because society fails to respond adequately to male victimization. As Steve explains, "unless I was physically gushing blood and the ambulance came and the police came, I really can't see them caring." Both male and female providers referred to a sustained idea among sex workers that police believe violence is merely part of the sex industry. Indeed, asymmetrical criminalization is based on this idea-that violence is inherent to sex work-making it harder for sex workers to access justice when violence does occur.
Like the female participants of the larger sample, the male interviewees highlighted the importance of workplace training and information-sharing to ensure workplace safety. As with any form of labour, training regarding safe workplace practices decreases the risk of workplace injuries. In the case of sex work, thirdparties are criminalized for providing such information, leaving sex workers to implement safety strategies on a client-to-client basis without formal training. Authors such as Abel et al. (2009), Krüsi et al. (2014), and Pivot Legal Society (2006) point out the dangers workers face when safety strategies are constrained. Participants in the current study, echoing sex workers demands for decades (Beer 2018), advance that decriminalization would permit the extension of labour rights and facilitate the improvement of safe working conditions through workplace training and operations standards. As John explains:

I can't understand why it would be associated with criminal activity. I simply don't understand and I am involved in it.... It would be better to have environments where the transactions can take place and where they aren't regarded as dirty, subterranean and shameful.

\section{Occupational Health and Safety}

\section{Stigma}

I think if [sex work] was not taboo, I wouldn't have a problem with everybody knowing. But it is. Sex is a taboo subject itself-getting paid for sex just ups the ante. (Jared)

While stigma is felt differentially, reflecting levels of social privilege or oppression associated with one's socio-political identity, all sex workers deal with stigma (Bruckert and Hannem 2013; Bowen and Bungay 2016; Day 2007). Female participants characterized stigma as being one of the worst occupational hazards of their work. Men, too, felt stigma associated with selling sex, and gay men felt doubly stigmatized for being gay and providing services to other men. Some participants asserted that judgments about sex work as criminal behaviour jeopardized safe workspaces. If a landlord learns sex work is 
occurring on premises of a rented space, the landlord is considered to be materially benefitting from sex work, which is a criminal offence in Canada. Sean reported being evicted from a workspace on precisely this basis.

FSWs in general may experience worse consequences resulting from stigma than do MSWs. Greater visibility of female street-based sex work contributes to increased police presence and therefore increased negative encounters with police (Ross 2010; Bruckert and Hannem 2013; Shaver 2005). Justified by their concern for the exploitation of women, heightened police attention has resulted in a greater likelihood that police will target FSWs for intervention (Jeffrey and MacDonald 2006). Sex work involvement can, and continues to be, used against sex workers in civil proceedings as a demonstration of poor judgment and a lack of fitness for parenting (O'Doherty 2015; Ross 2010).

Stigma prevents sex workers from experiencing the same civic and social rights afforded to other members of society (Bruckert and Hannem 2013). This exclusion from society prevents all sex workers from being able to practice their work in ways that maximize their occupational safety. For instance, they may be less likely to seek out medical attention and report victimization for fear of facing discrimination by police and health practitioners because of their involvement in the sex industry. In our interviews, Dave pointed out that decriminalization alone would not eliminate stigma just as decriminalization did not eliminate homophobia. However, it would allow sex work to be legitimate, thereby increasing sex workers' ability to practice sex work safely.

\section{Isolation and its Effects on Health}

Isolation is another occupational hazard of sex work, particularly independent sex work. The secretive and stigmatized nature of the work makes many sex workers fear being "outed" by family or friends (Bowen 2015), forcing them to lead isolating "double lives." The job itself can leave sex workers feeling emotionally and physically drained by the time they return home, creating distance in personal lives. Damien indicated that he was very careful about when and to whom he disclosed his sex work, "because then they can't see the rest of me." All participants, regardless of gender, reported experiencing strained personal relationships with partners and in some cases, their families.

Isolation may be a greater factor for MSWs. Several of the male participants commented to the effect that they did not have the same support networks as female providers, even voicing uncertainty about whether organizations would provide services to male providers. Further, FSWs have more opportunity to work with other sex workers and third parties, which can help to mitigate the effects of isolation. Of course, working with others is criminalized in Canada and opens sex workers up to increased possibility of law enforcement action.

\section{Health Outcomes}

In terms of physical health, MSWs and FSWs identified sexually transmitted infections as being a serious occupational health hazard. Most participants stressed the importance of safe sex practices, yet some explained that contracting an STI was simply a part of the job. Research has consistently determined that sex workers take safe sex practices seriously (McCarthy, Benoit, and Jansson 2014; Parent and Bruckert 2013; Parsons, Koken, and Bimbi 2007; Walby 2012). However, Atchison and Burnett (2016) add that safe sex practices are dictated by a multitude of factors like venue, clients' relationships, and choices related to substance abuse. Since FSWs are more likely to work in street-based settings, Weitzer (2009) concludes that they have a harder time mitigating risky behaviours because there is a higher prevalence of drug use, coercion, and violence. Further, some providers may be at higher risk of engaging in unsafe sexual practices due to rushed negotiations that result from fear of police (Pivot Legal Society 2006).

Regarding other health outcomes, sex work is emotional labour. Some participants, like Nico, attributed 
feelings of depression to the stigma and isolation that permeates the sex industry. He explains:

I do have some depression around escorting. ... My boyfriend, I was with him for a year and a half. He never told me to stop [working] ... but I knew at the end of the relationship, this [being an escort] was the issue.

Sex workers create physical, social, and psychological boundaries to keep their work and personal lives separate (Smith, Grov, and Seal 2008); maintaining these boundaries can be mentally draining and isolating. FSWs in general face higher levels of stress due to fear of police intervention and prosecution. While some of the male participants mentioned their fear of having their sex worker identity exposed, this was not as prominent a concern for the men since they rarely feared police prosecution. Thus, there may be a gendered difference in the severity of emotional, physical, and psychological consequences of sex work under criminalized regulation.

\section{Regulatory Approaches}

\section{Understanding of Criminal Laws and their Effects}

The male interview participants reported having mostly indifferent relationships with the law and law enforcement. Many participants expressed that police were more interested in targeting female providers, which may explain why a majority had never encountered law enforcement and felt minimal concern about criminalization. Consequently, the male subset of the larger sample was better able to perform their work without fear of police persecution, affording them increased control over their work environments. They could work from home and communicate with clients more openly, thereby reducing the number of occupational hazards they encounter.

In contrast, the female participants expressed that sex work laws greatly impacted their work. For instance, heightened efforts to rescue them from the industry can generally make FSWs more hesitant to work out of their homes, forcing them to navigate unsafe working conditions like poorly lit, less-populated areas to find clients or outcall locations-environments that increase the risk of violent victimization (Pivot Legal Society 2006).

Some participants understood this differential enforcement of the law as speaking to the societal construction of gender difference that is replicated in commercial sex. Specifically, when societies associate gender with vulnerability-for example portraying women as inherently vulnerable to victimization and exploitation-protectionist policies emerge. The creation of such policies has led some participants, like Marco, to argue that the male and female industries should be subject to different laws: "[T]hey are entirely different sex industries. They are entirely different professions, [and] trying to make laws that think of both; it's wrong. It's making mistakes again and again and again.”

In our survey, gender did not affect the levels of fear reported when sex workers crossed international borders. All providers reported feeling very anxious when crossing the Canadian/United States border due to fear that the border guard would inquire about their work and uncover their involvement in the sex industry. To navigate those situations, participants reported that they described their work in vague terms and prepared answers ahead of time to help ease their apprehension.

While all participants expressed limited knowledge of the specific laws surrounding the Canadian sex industry, the female participants more often knew general information, with a few participants having strong knowledge of the law. In contrast, and similar to Corriveau and Greco's (2014) findings, the male participants displayed limited, if any, knowledge of current laws, or even whether their work was legal. This ability to work without knowing current legal frameworks speaks to advantages of being male and selling sex: there is less societal attention and differential law enforcement. In this way, their gender insulates men from police surveillance, thereby shaping their experiences. 
Approaching Sex Work as Work

All participants expressed views of their work as labour, and as a form of labour that extended beyond the provision of sexual services. Many described their work as similar to the work of therapists, entertainers, or caregivers, underscoring the healing, caring, and therapeutic benefits that their clients receive. John, described the importance of his work:

The men I see have a chance to experience something that, for whatever reason, they have chosen to repress. It could be that they're afraid to acknowledge themselves or represent themselves as gay because of fears at work or family. They get one moment, whether it's an hour, three hours, a weekend, to experience what it might be like to live the life they wish they could live.

Examining the intricacies of the industry in terms of its labour components demonstrates that sex workers generally approach their work as they would any other business venture. Much like other self-employed business owners, participants discussed having to track expenses, advertise their services, market themselves, and behave in a professional manner to succeed. While some minor gender differences may exist, our data reveals that prioritizing overarching labour issues instead of gendered experiences working in the sex industry can function to increase worker safety.

\section{Conclusion}

The overwhelming majority of participants in this study expressed that sex work ought to be recognized as work, and that any form of criminalization impedes access to justice and human and labour rights. The majority of male and female participants did not experience violence from clients, and when they experienced victimization, it most often manifested in the form of harassment. Safety-enhancing strategies used by more privileged sex workers safeguard their occupational health and contribute to lower rates of violence. However, female participants clearly prioritize these efforts at a higher level than do the male participants, indicating a clear gender disparity regarding fear of violence.
Unsurprisingly, a key difference between the gender groups is real and perceived vulnerability to violence and victimization. While neither group faced high rates of violence, female providers adopt more comprehensive risk management tools and report greater interaction with police. MSWs felt safer carrying out their work than FSWs did, which afforded them less stress and fear in relation to their work. These results clearly indicate that gender insulated men from some of the victimization experienced by women. However, victimization rates vary based on other social and contextual factors too, demonstrating that rather than commercial sex itself being a source of victimization, the industry replicates victimization rates seen across all forms of labour. In this regard, the sex industry is no different from other industries in terms of the impacts of intersecting levels of oppression.

This data highlights how gender privilege functions to insulate men from some forms of interpersonal violence, but they also show the differential application of the law to the male and female commercial sex industries. Responses of the male participants indicate an entitlement to delineating the parameters of their sexual activities, whether personal or professional. These are privileges that women have to fight for and defend. Many other layers of oppression and disadvantage function in similar ways to insulate some from-and expose others to-harsher working conditions, exploitation, and violence.

If policy-makers wish to improve sex workers' access to justice, they need to incorporate knowledge about how other layers of oppression, such as racism, classism, ableism, or heterosexism impact the job of sex work, law enforcement, and related victimization rates. The effects of oppression are amplified because the commercial sex industry is subject to criminal laws and its labourers do not have recourse under labour or human rights laws. Thus, the criminalization of the sex industry has differential impacts on the safety and occupational health of male and female sex workers. If nations are looking to protect individuals from violence and exploitation, they must consider how laws and law enforcement contribute to victimization and 
vulnerability among multiple and intersecting layers of oppression. If access to justice for the most advantaged of sex workers remains elusive, where does that leave those who live with less privilege?

\section{References}

Abel, Gillian M., Lisa J. Fitzgerald, and Cheryl Brunton. 2009. "The Impact of Decriminalisation on the Number of Sex Workers in New Zealand." Journal of Social Policy 38 (3). Cambridge University Press: 515-31.

https://doi.org/10.1017/S0047279409003080.

Allman, D. 1999. $M$ is for mutual, $A$ is for Acts: Male Sex Work and AIDS in Canada. Health Canada / AIDS Vancouver / Sex Workers Alliance of Vancouver / HIV Social, Behavioural and Epidemiological Studies Unit, University of Toronto.

Anderson, Solanna, Jessica Xi Jia, Vivian Liu, Jill Chattier, Andrea Krüsi, Sarah Allan, Lisa Maher, and Kate Shannon. 2015. "Violence Prevention and Municipal Licensing of Indoor Sex Work Venues in the Greater Vancouver Area: Narratives of Migrant Sex Workers, Managers and Business Owners." Culture, Health and Sexuality 17 (7): 825-41. https://doi.org/10.1080/13691058.2015.1008046.

Atchison, Chris, and Patrick John Burnett. 2016. "The Social Dynamics of Safe Sex Practices among Canadian Sex Industry Clients." Sociology of Health and Illness 38 (6): 939-56. https://doi.org/10.1111/1467-9566.12416.

Beer, S. 2018. "Action, Advocacy, and Allies: Building a Movement for Sex Worker Rights." In Red Light Labour: Sex work, Regulation, Agency and Resistance, 329-339. Vancouver: UBC Press.

Benoit, Cecilia, Chris Atchison, Lauren Casey, Mikael Jansson, Bill Mccarthy, Rachel Phillips, Bill Reimer, Dan Reist, and Frances M. Shaver. 2014. "Building on the Evidence: An International Symposium on the Sex Industry in Canada (Updated)." http://www.nswp.org/sites/nswp.org/files/Gender $\% 2$ $\mathrm{C}$ Violence and Health - Contexts of vulnerability $\% 2 \mathrm{C}$ resiliencies and care among people in the sex industry in Canada.pdf. 
Bimbi, David S. 2007. "Male Prostitution: Pathology, Paradigms and Progress in Research." Journal of Homosexuality 53 (1-2): 7-35.

https://doi.org/10.1300/J082v53n01_02.

Bowen, Raven. 2015. "Squaring Up: Experiences of Transition from Off-Street Sex Work to Square Work and Duality-Concurrent Involvement in Both-in Vancouver, BC." Canadian Review of Sociology 52 (4): 429-49. https://doi.org/10.1111/cars.12085.

Bowen, Raven, and Vicky Bungay. 2016. "Taint: An Examination of the Lived Experiences of Stigma and its Lingering Effects for Eight Sex Industry Experts." Culture, Health \& Sexuality 18 (2): 186-99. https://doi.org/10.1080/13691058.2015.1072875.

Bowen, R. and Tamara O'Doherty. 2014. "Participant-Driven Action Research (PDAR) with Sex Workers in Vancouver." In C. Showden \& S. Majic (Eds.) Negotiating Sex Work: Unintended Consequences of Policy and Activism, 53-74. Minneapolis: University of Minnesota Press.

Bruckert, Chris, and Stacey Hannem. 2013. "Rethinking the Prostitution Debates: Transcending Structural Stigma in Systemic Responses to Sex Work." Canadian Journal of Law and Society 28 (1): 43-63. https://doi.org/10.1017/cls.2012.2.

Bruckert, Chris, and Tuulia Law. 2013. "Beyond Pimps, Procurers and Parasites: Mapping Third Parties in the Incall/Outcall Sex Industry." Ottawa. http:/www.nswp.org/sites/nswp.org/files/Manageme ntResearch \%284\%29.pdf.

Bungay, Vicky, Michael Halpin, Peter F. Halpin, Caitlin Johnston, and David M. Patrick. 2012. "Violence in the Massage Parlor Industry: Experiences of Canadian-Born and Immigrant Women." Health Care for Women International 33 (3): 262-84.

https://doi.org/10.1080/07399332.2011.603868.

Canada (Attorney General). v. Bedford [2013] SCC 72.
Corriveau, Patrice, and Christopher Greco. 2014. "Misunderstanding (Mis)Understandings: Male Sex Workers and the Canadian Criminal Code." Sexuality and Culture 18 (2): 346-60.

https://doi.org/10.1007/s12119-013-9201-6.

Day, S. 2007. On the Game: Women and Sex Work. London: Pluto Press.

Dorais, M. 2005. Rent Boys: The World of Male Sex Workers. Quebec: McGill-Queen's University Press.

Fletcher, T. 2013. "Trans Sex Workers: Negotiating Sex, Gender, and Non-Normative Desire." In Selling Sex: Experience, Advocacy, and Research on Sex Work in Canada, 65-73. Vancouver: UBC Press.

Gratl, Jason. 2012. “'Wouldn't Piss On Them If They Were On Fire': How Discrimination Against Sex Workers, Drug Users and Aboriginal Women Enabled a Serial Killer." Independent Counsel to the Commissioner of the Missing Women Commission of Inquiry.

https://www.scribd.com/document/103641727/Indep endent-Counsel-Report-to-Commissioner-of-InquiryAugust-16-2012.

Jeffrey, Leslie and Gayle MacDonald. 2006. Sex Workers in the Maritimes Talk Back. Vancouver: UBC Press

Jenkins, S. 2009. Beyond Gender: An Examination of Exploitation in Sex Work. Doctoral Dissertation: Keele University.

Jones, Angela. 2015. "For Black Models Scroll Down: Webcam Modeling and the Racialization of Erotic Labor." Sexuality \& Culture 19: 776-99. https://doi.org/10.1007/s12119-015-9291-4.

Krüsi, A., K. Pacey, L. Bird, C. Taylor, J. Chettiar, S. Allan, D. Bennett, J. S. Montaner, T. Kerr, and K. Shannon. 2014. "Criminalisation of Clients: Reproducing Vulnerabilities for Violence and Poor Health among Street-Based Sex Workers in Canada - 
A Qualitative Study.” BMJ Open 4 (6): 1-10.

https://doi.org/10.1136/bmjopen-2014-005191.

Kumar, Navin, Victor Minichiello, John Scott, and Taylor Harrington. 2017. "A Global Overview of Male Escort Websites." Journal of Homosexuality 64 (12): $1731-44$.

https://doi.org/10.1080/00918369.2016.1265356.

Kurtz, Steven P., Hilary L. Surratt, James A. Inciardi, and Marion C. Kiley. 2004. "Sex Work and 'Date' Violence." Violence Against Women 10 (4): 357-85. https://doi.org/10.1177/1077801204263199.

Lam, Elene. 2018. "Behind the Rescue: How AntiTrafficking Investigations and Policies Harm Migrant Sex Workers."

http://www.nswp.org/sites/nswp.org/files/behind_the _rescue_june_2_butterfly.pdf.

Landsberg, Adina, Kate Shannon, Andrea Krüsi, Kora DeBeck, M. J. Milloy, Ekaterina Nosova, Thomas Kerr, and Kanna Hayashi. 2017.

"Criminalizing Sex Work Clients and Rushed Negotiations among Sex Workers Who Use Drugs in a Canadian Setting." Journal of Urban Health 94 (4): 563-71. https://doi.org/10.1007/s11524-017-01550.

Levy, Jay, and Pye Jakobsson. 2014. “Sweden's Abolitionist Discourse and Law: Effects on the Dynamics of Swedish Sex Work and on the Lives of Sweden's Sex Workers." Criminology \& Criminal Justice 14 (5): 593-607. https://doi.org/10.1177/1748895814528926.

Lewis, Jacqueline, Eleanor Maticka-Tyndale, Frances Shaver, and Heather Schramm. 2005. "Managing Risk and Safety on the Job." Journal of Psychology \& Human Sexuality 17 (1-2). The Haworth Press: 14767. https://doi.org/10.1300/J056v17n01_09.

Lowman, John. 2000. "Violence and the Outlaw Status of (Street) Prostitution in Canada." Violence Against Women 6 (9): 987-1011. https://doi.org/10.1177/10778010022182245.

Lyons, Tara, Andrea Krüsi, Leslie Pierre, Will Small, and Kate Shannon. 2017. "The Impact of

Construction and Gentrification on an Outdoor Trans Sex Work Environment: Violence, Displacement and Policing." Sexualities 20 (8): 881-903. https://doi.org/10.1177/1363460716676990.

MacPhail, Catherine, John Scott, and Victor Minichiello. 2015. "Technology, Normalisation and Male Sex Work." Culture, Health and Sexuality 17 (4): 483-95. https://doi.org/10.1080/13691058.2014.951396.

Maher, Janemaree, Sharon Pickering, and Alison Gerard. 2012. "Privileging Work Not Sex: Flexibility and Employment in the Sexual Services Industry." Sociological Review 60 (4): 654-75. https://doi.org/10.1111/j.1467-954X.2012.02128.x.

Mariño, Rodrigo, Victor Minichiello, and Carlos Disogra. 2004. "A Profile of Clients of Male Sex Workers in Córdoba, Argentina." International Journal of STD and AIDS 15 (4): 266-72.

https://doi.org/10.1258/095646204773557811.

McCarthy, Bill, Cecilia Benoit, and Mikael Jansson. 2014. "Sex Work: A Comparative Study." Archives of Sexual Behavior 43 (7): 1379-90.

https://doi.org/10.1007/s10508-014-0281-7.

McCarthy, Bill, Cecilia Benoit, Mikael Jansson, and Kat Kolar. 2012. "Regulating Sex Work:

Heterogeneity in Legal Strategies." Annual Review of Law and Social Science 8 (1): 255-71.

https://doi.org/10.1146/annurev-lawsocsci-102811173915.

McIntyre, Susan. 2005. "Under the Radar: The Sexual Exploitation of Young Men-Western Canadian Edition."

http://www.humanservices.alberta.ca/documents/child -sexual-exploitation-under-the-radar-westerncanada.pdf. 
Meulen, Emily van der, Jessica Yee, and Elya M Durisin. 2010. "Violence against Indigenous Sex Workers. Combating the Effects of Criminalisation and Colonialism in Canada." Research for Sex Work: Sex Work and Violence, no. 12: 35-38. http://www.nswp.org/sites/nswp.org/files/researchfor-sex-work-12-english-russian_0.pdf.

Minichiello, Victor, Rodrigo Mariño, Jan Browne, Maggie Jamieson, Kirk Peterson, Brad Reuter, and Kenn Robinson. 1999. "A Profile of the Clients of Male Sex Workers in Three Australian Cities." Australian and New Zealand Journal of Public Health 23 (5): 511-18. https://doi.org/10.1111/j.1467842X.1999.tb01308.x.

Minichiello, Victor, John Scott, and Denton Callander. 2013. "New Pleasures and Old Dangers: Reinventing Male Sex Work." Journal of Sex Research 50 (3-4): 263-75.

https://doi.org/10.1080/00224499.2012.760189.

O'Doherty, Tamara. 2007. Off-Street Commercial Sex: An Exploratory Study. Master's thesis, Simon Fraser University.

- 2011. "Criminalization and Off-Street Sex Work in Canada." Canadian Journal of Criminology and Criminal Justice 53 (2): 217-45.

https://doi.org/10.3138/cjccj.53.2.217.

- 2015. Victimization in the Canadian offStreet Sex Industry. Doctoral dissertation, Simon Fraser University.

Parent, Colette, and Chris Bruckert. 2013. "The Work of Sex Work.” In Sex Work, 57-80. Vancouver: UBC Press.

Parsons, JT, JA Koken, and DS Bimbi. 2007. "Looking beyond HIV: Eliciting Individual and Community Needs of Male Internet Escorts." Journal of Homosexuality 53 (1-2). The Haworth Press The Haworth Press, Inc: 219-40. https://doi.org/10.1300/J082v53n01.
Pendleton, Mark, and Luca Stevenson. 2016. Male Sex Work and Society. Edited by Victor Minichiello and John Scott. Vol. 18. New York: Columbia University Press.

https://doi.org/10.1080/13691058.2015.1070609.

Pitcher, Jane. 2015. "Sex Work and Modes of SelfEmployment in the Informal Economy: Diverse Business Practices and Constraints to Effective Working." Social Policy and Society 14 (1): 113-23. https://doi.org/10.1017/S1474746414000426.

Pitcher, Jane, and Marjan Wijers. 2014. “The Impact of Different Regulatory Models on the Labour Conditions, Safety and Welfare of Indoor-Based Sex Workers." Criminology and Criminal Justice 14 (5): 549-64.

https://doi.org/10.1177/1748895814531967.

Pivot Legal Society. 2006. "Beyond Decriminalization: Sex Work, Human Rights, and a New Framework for Law Reform." Human Rights.

http://d3n8a8pro7vhmx.cloudfront.net/pivotlegal/leg acy_url/275/BeyondDecrimLongReport.pdf?1345765 615.

Raguparan, Menaka. 2017. "If I'm Gonna Hack Capitalism': Racialized and Indigenous Canadian Sex Workers' Experiences within the Neo-Liberal Market Economy." Women's Studies International Forum 60 (January-February): 69-76.

https://doi.org/10.1016/j.wsif.2016.12.003.

Redwood, River. 2013. "Myths and Realities of Male Sex Work: A Personal Perspective." In Selling Sex: Experience, Advocacy, and Research on Sex Work in Canada, 45-57. Vancouver: UBC Press.

Ross, Becki L. 2010. "Sex and (Evacuation from) the City: The Moral and Legal Regulation of Sex Workers in Vancouver's West End, 1975-1985." Sexualities 13 (2): 197-218. https://doi.org/10.1177/1363460709359232.

Sanders, Teela, Jane Scoular, Rosie Campbell, Jane 
Pitcher, and Stewart Cunningham. 2018. Internet Sex Work: Beyond the Gaze. Switzerland: Palgrave MacMillan.

Shaver, Frances M. 2005. "Sex Work Research:

Methodological and Ethical Challenges." Journal of Interpersonal Violence 20 (3): 296-319.

https://doi.org/10.1177/0886260504274340.

Shaver, Frances M., Jacqueline Lewis, and Eleanor Maticka-Tyndale. 2011. "Rising to the Challenge: Addressing the Concerns of People Working in the Sex Industry." Canadian Review of Sociology 48 (1): 47-65. https://doi.org/10.1111/j.1755-

618X.2011.01249.x.

Smith, M, Christian Grov, and David Seal. 2008. "Agency-Based Male Sex Work: A Descriptive Focus on Physical, Personal, and Social Space." The Journal of Men's Studies 16 (2): 193-210.

https://doi.org/10.3149/jms.1602.193.

Smith, N. 2012. "Body Issues: The Political Economy of Male Sex Work." Sexualities 15 (5-6):586-603. https://doi.org/10.1177/1363460712445983.

Walby, Kevin. 2012. Touching Encounters: Sex, Work and Male for Male Internet Escorting. Chicago: University of Chicago Press.

Waters, Ian. Off-Street Male Sex Work: Canadian Experiences and Perspectives. Honour's thesis, Simon Fraser University, 2018.

Weitzer, Ronald. 2009. "Sociology of Sex Work." Annual Review of Sociology 35 (1): 213-34. https://doi.org/10.1146/annurev-soc-070308-120025. 